\title{
SCREENING METHOD FOR COLONY-STIMULATING FACTOR INDUCERS USING A HUMAN BONE MARROW STROMAL CELL LINE, KM-102
}

\author{
Takafumi Kohama, Hiroko Miyaoka a , Akio Torikata ${ }^{a}$, Masatoshi InUKai ${ }^{a}$, \\ Isao Kaneko and Akio Shiraishi \\ Bioscience Research Laboratories, \\ ${ }^{a}$ Fermentation Research Laboratories, Sankyo Co., Ltd., \\ 1-2-58 Hiromachi, Shinagawa-ku, Tokyo 140, Japan
}

(Received for publication March 5, 1993)

\begin{abstract}
A new screening method for inducers of colony-stimulating factors (CSFs) was established using KM-102, a human bone marrow stromal cell line as the producer. In this method, the assay system which uses CSF dependent cell lines is combined with the CSF production system. Interleukin-1 (IL-1), which is known to upregulate CSF production in many cell populations, was used as a positive control for production of granulocyte CSF (G-CSF) and granulocyte-macrophage CSF (GM-CSF). Induction in the positive controls was clearly detected within 24 hours. Activators of protein kinase $\mathrm{C}$ (PKC), protein phosphatase inhibitors and lipopolysaccharide (LPS) were positive in this assay system, but muramyl dipeptide (MDP) and Bestatin which are known macrophage activators, were negative.

Inducers of CSFs were successfully detected using this assay method. Among 1,600 microbial strains tested, 2 actinomycete strains were found to produce active substances. One strain produces teleocidin- $\mathrm{A}$, a strong activator of $\mathrm{PKC}$, and the other strain produces a mixture of active compounds including three novel compounds. These three compounds do not induce terminal differentiation of HL-60 cells, suggesting that they are not teleocidin-like substances and form a new class of CSF inducers.
\end{abstract}

The colony-stimulating factors (CSF) are a class of glycoprotein hormones that regulate the formation and function of blood cells ${ }^{1,2)}$. Recent clinical trials revealed that they have shown salutary impact in the prevention of chemotherapy induced neutropenia and in the treatment of cytopenias associated with several hematological syndromes including AIDS $^{3)}$. But little is known about the regulatory mechanisms for the production of CSFs in vivo.

Some immunomodulators derived from microorganisms induce CSF production by several kinds of cells, especially macrophages, and they have been used for the treatment of hematopoietic disorders. For example, muroctasin (MDP derivative) ${ }^{4 \sim 6)}$ has been used in the treatment of leukopenias, and Bestatin in the treatment of leukemia ${ }^{7}$. Both compounds are known to stimulate CSF production by macrophages ${ }^{8 \sim 11)}$. However, upregulation of blood cell formation by these compounds is relatively weak compared with that by CSF itself. In normal adults, bone marrow is the major hematopoietic tissue, and blood cell formation is regulated by positive and negative factors in the bone marrow ${ }^{12)}$. Therefore, the most effective in vivo agents are likely to be substances that upregulate the concentration of CSFs in the bone marrow, but the effects of the above immunomodulators on upregulation of CSFs in bone marrow are not clear.

Substances that specifically stimulate the production of CSFs by stromal cells may accelerate blood cell formation in vivo more effectively than the above non-specific CSF inducers. This notion is supported by the fact that stromal cells in bone marrow play an important role in the regulation of hematopoiesis ${ }^{13)}$ through cell-cell interaction and release of hematopoietic growth factors ${ }^{12,14 \sim 16)}$. Furthermore, bone 
marrow specificity of such a substance may reduce several side-effects which are observed in patients administrated non-specific CSF inducers or CSF itself. These side effects (fever, inflammation at the site of injection, rigor, etc.) are caused by the increased level of CSFs at the injection site or in inappropriate tissues and by the production of monokines through the activation of macrophages.

HARIGAYA et al. established several clonal human bone marrow stromal cell lines by transfection with plasmid DNA containing the simian virus 40 (SV40) early region ${ }^{14)}$. KM-102, one of these immortalized stromal cell lines, is known to produce viarious hematopoietic factors ${ }^{15,17,18)}$, and therefore is a useful tool for the screening of CSF inducers instead of primary human bone marrow stromal cells.

In this report we describe the primary screening method for CSF inducers using KM-102 cells, the effects of various known compounds in this screening system, and the inducers discovered by this screening program.

\section{Materials and Methods}

Cells, Cytokines and Antibodies

KM-102 ${ }^{14)}$ was kindly supplied by Dr. K. Harigaya, Chiba Univ., Chiba, Japan. TF-1 ${ }^{19)}$, a granulocyte-macrophage CSF (GM-CSF) dependent cell line from bone marrow cells of a patient with erythroleukemia, was kindly supplied by Dr. T. KITAMURA, Dnax Research Institute, USA. NFS-60 ${ }^{20)}$ a granulocyte CSF (G-CSF) dependent cell line from a wild-mouse murine leukemia virus-induced tumor, was kindly supplied by Dr. J. N. IHLE, National Cancer Institute, USA. Human recombinant GM-CSF and interleukin-1 $\beta$ (IL-1 $\beta$ ) were purchased from Genzyme (Boston, USA). Human recombinant G-CSF (Gran; Sankyo, Japan) was used. Antibodies against G- and GM-CSF used are described in the accompanying paper ${ }^{21)}$

\section{Cell Cultures}

KM-102 was maintained in Iscove's medium (Boehringer Mannheim) supplemented with $5 \%$ fetal bovine serum (FBS) (5\% FBS-IMDM). TF-1 was maintained in 5\% FBS-IMDM containing 10 units $/ \mathrm{ml}$ of human recombinant GM-CSF. NFS-60 was maintained in 5\% FBS-IMDM supplemented with 5\% WEHI- 3 conditioned medium. All cell lines were grown in a humidified incubator $\left(95 \%\right.$ air $\left.-5 \% \mathrm{CO}_{2}\right)$ at $37^{\circ} \mathrm{C}$.

\section{Preparation of Screening Samples}

Microbial culture broth was extracted with an equal volume of ethylacetate at $\mathrm{pH} 3.0$ and then dried. The residue was then dissolved in methanol at $1 / 10$ of the original volume.

Fig. 1. A schematic drawing of the screening method.

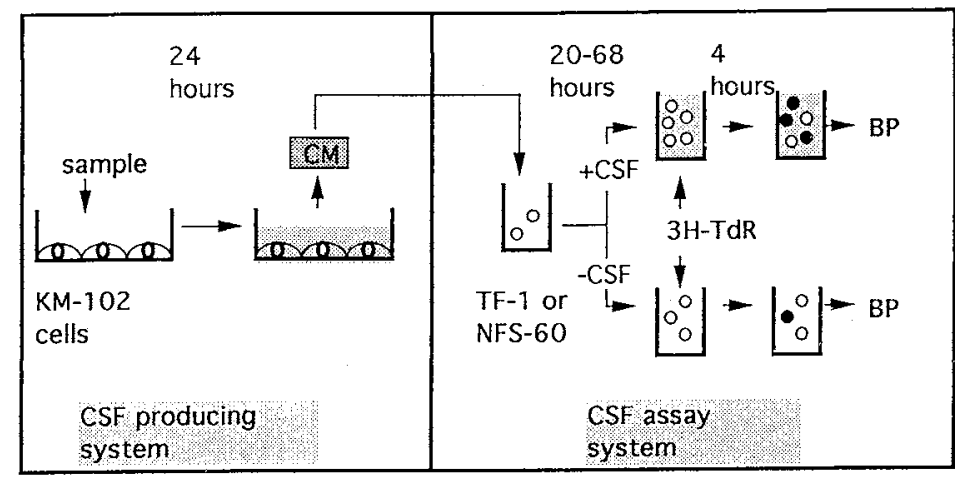


Screening Method

CSF producing system: The screening method for CSF inducers is summarized in Fig. 1. The culture samples dissolved in methanol $(2 \sim 20 \mu \mathrm{l})$ were placed in separate wells of a collagen-coated 96-well microplate (Corning, USA) and dried. Then KM-102 cells $\left(4 \times 10^{4}\right.$ cells in $200 \mu 1$ of $5 \%$ FBS-IMDM) were seeded in each well. The cells were incubated for 24 hours. Then, the conditioned media (CM) were collected and transfered to the CSF assay system.

CSF assay system: The quantities of GM-CSF and G-CSF produced by KM-102 were estimated by the methods of Kitamura et al. ${ }^{19)}$ and SHIRAFurr et al. ${ }^{22)}$, respectively. The amounts of standard CSFs required to support half maximal $\left[{ }^{3} \mathrm{H}\right]$ thymidine uptake were about $200 \mathrm{pg} / \mathrm{ml}$ of G-CSF for NFS-60 cell growth and $10 \mathrm{pg} / \mathrm{ml}(1 \mathrm{unit} / \mathrm{ml})$ of GM-CSF for TF-1 cell growth. Maximal growth of factor-dependent cells were observed at a concentration 5-fold higher than half maximal dose. Appropriate volumes $(10 \mu \mathrm{l}$ for TF-1 assay and $20 \mu \mathrm{l}$ for NFS-60 assay) of each KM-102 CM were placed in separate wells of a round-bottomed 96-well microplate (Corning, USA). Factor dependent cell lines of TF-1 and NFS-60 $\left(5 \times 10^{3}\right.$ cells in $200 \mu$ l of $5 \%$ FBS-IMDM at the final concentration) were added to each well. Cultures were incubated for 24 to 72 hours. For the final 4 hours of incubation, the cells were pulsed with $1 \mu \mathrm{Ci}$ $\left[{ }^{3} \mathrm{H}\right]$ thymidine (5 Ci/mmol; Amersham, England). $\left[{ }^{3} \mathrm{H}\right]$ thymidine incorporation was measured by the betaplate system (BP; Pharmacia Fine Chemicals, Uppsala, Sweden) as an indicator of growth in the factor dependent cells. Thus, incorporation of $\left[{ }^{3} \mathrm{H}\right]$ thymidine by TF- 1 and NFS- 60 cells reflected the CSF induction by the KM-102 cells in the producing system.

\section{Chemicals}

Bioactive compounds were obtained from the following sources: okadaic acid, calyculin $\mathrm{A}$ and palytoxin, Wako pure chemical industries, LTD.; teleocidin B4, indolactamV(-) and indolactamV $(+)$, Seikagaku Kogyo Co., LTD. lipopolysaccharide (LPS), Difco; Bestatin, phorbol myristoyl acetate (PMA), mezerein, dibutyryl cAMP, forskolin, A23187, rubratoxin B and paturin, Sigma. Other mycotoxins were generous gifts of Dr. S. TAKAHASHI, Fermentation Research Laboratories, Sankyo Co. LTD.

\section{Results}

\section{Rationale for the Screening Method}

Determination of the optimal concentration of KM-102 cells: KM-102 cells were seeded in each well of a collagen coated 96-well microplate at $0.1 \sim 1.6 \times 10^{5}$ cells in $200 \mu \mathrm{l}$ of $5 \%$ FBS-IMDM. The cell concentration of $4.0 \times 10^{4}$ cells/well was most favorable for growth as assessed by crystal violet staining of viable cells and, thus, was adopted in subsequent experiments.

\section{Period of Induction}

In order to determine the optimal period of induction, time course studies were performed. IL-1 (10 units $/ \mathrm{ml})$ or a mixture of PMA $(10 \mathrm{ng} / \mathrm{ml})$ and ionophore A23187 $(0.2 \mu \mathrm{M})$ were used as inducers because each is known to upregulate CSF production by bone marrow stromal cells ${ }^{15,16,23,24)}$. The colony stimulating activities of KM-102 CM were measured by $\left[{ }^{3} \mathrm{H}\right]$ thymidine uptake of factor dependent cells. Fig. 2 shows the time courses of G- and GM-CSF production by KM-102 cells stimulated by several agents. IL-1 stimulated CSF activity in a time-dependent manner. After 24 hours incubation with IL-1, production of CSF activity began to approach a limit. Therefore, a 24 hours incubation was adopted in subsequent experiments. Antibodies against CSFs neutralized 90 95\% of CSF activity of KM-102 CM with or without CSF inducers. Some production of GM-CSF activity was observed in the absence of inducers (Fig. 2B), probably due to a low level of constitutive GM-CSF production by KM-102 cells ${ }^{15}$. The mixture of PMA and A23187 also induced CSF production, but was less potent than IL-1. Thus IL-1 used as a positive control. 
Fig. 2. The time courses of G- and GM-CSF production by KM-102 cells.

(A) G-CSF, (B) GM-CSF, O, no agent; •, IL-1 (10 units $/ \mathrm{ml})$; $\Delta$, mixture of PMA (10 ng/ml) and A23187 $(0.2 \mu \mathrm{M})$.

(A)

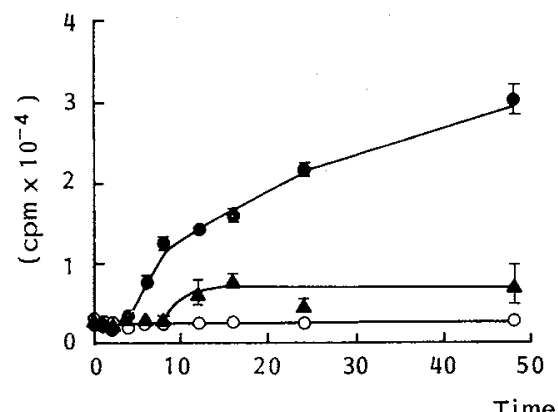

(B)

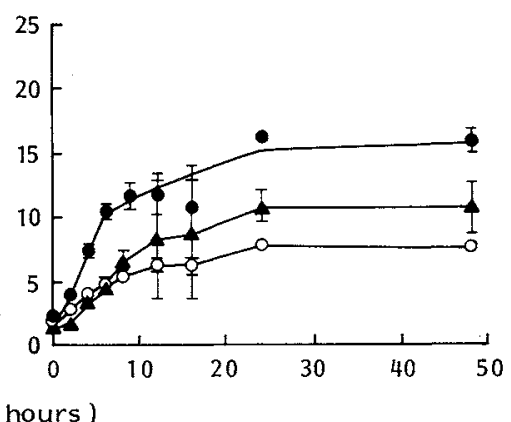

Activities of CSFs were measured as $\left[{ }^{3} \mathrm{H}\right]$ thymidine incorporation by factor dependent cell lines after stimulation.

\section{Determination of Optimal Conditions for the Assay Systems}

To reduce the effect of the spotaneous release of CSFs on the assay system, optimization of the volume of KM-102 CM was studied. We examined the effect of different volumes of KM-102 CM added to the assay systems. In the NFS-60 assay, addition of $20 \mu \mathrm{l}$ of KM-102 CM gave clear results. Thus, $20 \mu 1$ of KM-102 CM was adopted in subsequent experiments. In the case of the TF-1 assay, $10 \mu 1$ of KM-102 CM was optimal for screening.

\section{Effect of Known Compounds on G-CSF Production}

The effect of various known compounds (including mycotoxins, activators of $\mathrm{PKC}$, immunomodulators, phosphatase inhibitors, and other compounds that modulate signal transduction) on the production of G-CSF by KM-102 was tested. Table 1 shows the degree of maximal G-CSF activity induced by the appropriate concentration of each compound. Among the compounds that induced CSF production, IL-1 was the most potent agent. As shown in Fig. 3, addition of IL-1 (10 units $/ \mathrm{ml})$ resulted in a marked increase of G-CSF activity in KM-102 CM (equivalent to that of $1,000 \mathrm{pg} / \mathrm{ml}$ of human recombinant G-CSF). Treatment with activators of PKC resulted in moderate increases (approximately $20 \sim 40 \%$ of IL-1 treatment) in production of CSF activity. In the case of immunomodulators, LPS treatment resulted in moderate increases (approximately $50 \%$ of IL-1 treatment), but both MDP and Bestatin had no effect on G-CSF production by KM-102 cells (Fig. 4 and Table 1). Phosphatase inhibitors (okadaic acid and calyculin A) and cAMP-related agents (dibutyryl cAMP and forskolin) induced slight increases of G-CSF production by KM-102 cells (Fig. 5 and Table 1). Some of the mycotoxins (rubratoxin and PR-1388) also induced increases of G-CSF production by KM-102 cells (Table 1). Similar results were obtained using the GM-CSF bioassay. (data not shown).

\section{Results of Screening Run}

We screened the culture broths of about 1,600 strains of microbial soil isolates using our CSF inducing assay and found two actinomycete strains (A71902 and A71857) that produced active substances. An active substance, produced by A71902, was extracted with ethyl acetate and purified by reversed phase HPLC. UV absorption spectrum and MS spectrum of this substance were in good agreement with those 
Table 1. Effect of various compounds on the production of G-CSF by KM-102 cells.

\begin{tabular}{|c|c|c|c|}
\hline Compound & Effect & $\begin{array}{l}\text { Concentration induce } \\
\text { maximal CSF activity } \\
\qquad(\mathrm{ng} / \mathrm{ml})\end{array}$ & Function \\
\hline Interleukin-1 & ++ & 10 (units/m1) & Inflammatory cytokine \\
\hline Mezerein & + & 100 & Activator of $\mathrm{PKC}$ \\
\hline Teleocidin-B4 & + & 200 & Activator of $\mathrm{PKC}$ \\
\hline IndolactamV $(-)$ & + & 2,000 & Activator of PKC \\
\hline IndolactamV $(+)$ & - & - & \\
\hline A23187 & \pm & $4(\mu \mathrm{M})$ & Calcium ionophore \\
\hline Okadaic acid & \pm & 100 & Protein phosphatase inhibitor \\
\hline Calyculin A & \pm & 2.5 & Protein phosphatase inhibitor \\
\hline Palytoxin & - & - & Promotor \\
\hline Dibutyryl cAMP & \pm & 200 & cAMP analogue \\
\hline Forskolin & \pm & 100 & Adenylate cyclase activator \\
\hline LPS & + & 100,000 & Endotoxin (M $\phi$ activator) \\
\hline MDP & - & - & $\mathbf{M} \phi$ activator \\
\hline Bestatin & - & - & $\mathbf{M} \phi$ activator \\
\hline $\mathrm{LiCl}$ & - & - & \\
\hline Rubratoxin B & + & 20,000 & Mycotoxin \\
\hline PR-1388 & \pm & 2,000 & Mycotoxin \\
\hline Synerazol & - & - & Mycotoxin \\
\hline Mycophenol & - & - & Mycotoxin \\
\hline Pseurotin & - & - & Mycotoxin \\
\hline Borrelidin & - & - & Mycotoxin \\
\hline Paturin & - & - & Mycotoxin \\
\hline Brefelidin & - & - & Mycotoxin \\
\hline Radicicol & - & - & Mycotoxin \\
\hline Kojiic acid & - & - & Mycotoxin \\
\hline Neblarin & - & - & Mycotoxin \\
\hline Cerulenin & - & - & Mycotoxin \\
\hline Toluqunon & - & - & Mycotoxin \\
\hline Ovalicin & - & - & Mycotoxin \\
\hline
\end{tabular}

$++:$ Marked increase (value $\geq 70 \%$ of positive control (IL-1)), $+:$ moderate increase $(70 \%$ of positive control $>$ value $\geq 20 \%$ of positive control), \pm : slight increase $(20 \%$ of positive control $>$ value $\geq 2$ SD of negative control), $-:$ no increase (2SD of negative control $>$ value). The concentration of each compound tested are: mycotoxins and $\mathrm{LiCl} ; 20,2,0.2 \mu \mathrm{g} / \mathrm{ml}$, bestatin; $500,50,5 \mu \mathrm{g} / \mathrm{ml}$, A23187 20, 4, 0.8, 0.16 $\mu \mathrm{M}$, other compounds; refer to Fig. $3 \sim 5$.

of teleocidin A. Furthermore, this substance induced the terminal differentiation of HL-60 cells. Upon differentiation, the morphology of the HL-60 cells appeared similar to that of macrophages. These results indicate that this actinomycete strain (A71902) produces telecidin A.

The other strain (A71857) produces a mixture of active compounds including three novel products. These substances induced marked increases in CSF production comparable to IL-1 (Fig. 6), but showed no effect on the terminal differentiation of HL-60 cells. The results of the studies relating to these substances are published in accompanying papers.

\section{Discussion}

Since the discovery of penicillin, microbial metabolites have remained a good source of unique compounds and new medicines. As the utility of CSFs in medicine is generally recognized ${ }^{25}$, we searched for new inducers of CSF production from microbial sources.

Although many kinds of cells (e.g., macrophages, fibroblasts, endothelial cells and T-lymphocytes) 
Fig. 3. Effect of activators of PKC on G-CSF production by KM-102 cells.

O, IL-1; •, G-CSF $(1,000 \mathrm{pg} / \mathrm{ml}) ; \triangle$, indolactum $(-) ; \boldsymbol{\Delta}$, indolactum $(+) ; \square$, teleocidin-B4; $\mathbf{0}$, extract of A71902.

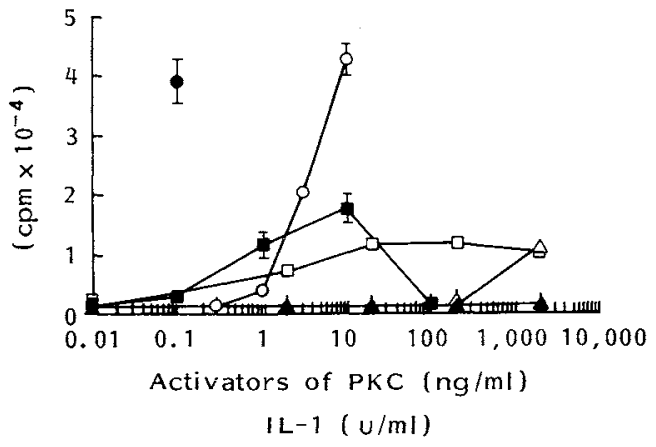

Broth extract ( $\%$ of original broth volume)

Fig. 5. Effect of various compounds on G-CSF production by KM-102 cells.

O, Palytoxin; - G-CSF $(1,000 \mathrm{pg} / \mathrm{ml}) ; \triangle$, forskolin; $\Delta$, DB-cAMP; $]$, okadaic acid; $\mathbf{E}$, calyculin-A.

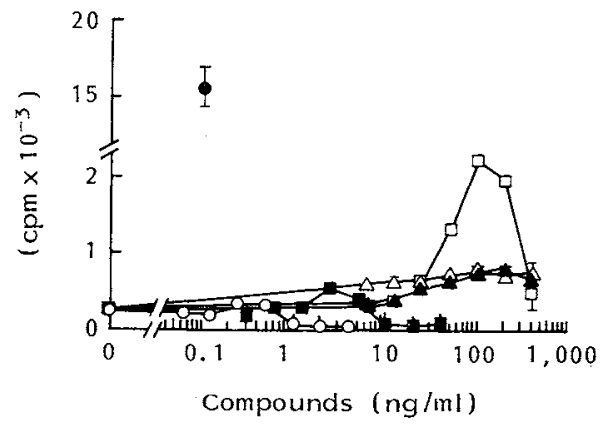

Fig. 4. Effect of immunomodulators on G-CSF production by KM-102 cells.

$$
\text { O, IL-1 (10 units/ml); } \triangle \text {, PMA; } \square, \text { MDP; } \mathbf{n} \text {, LPS. }
$$

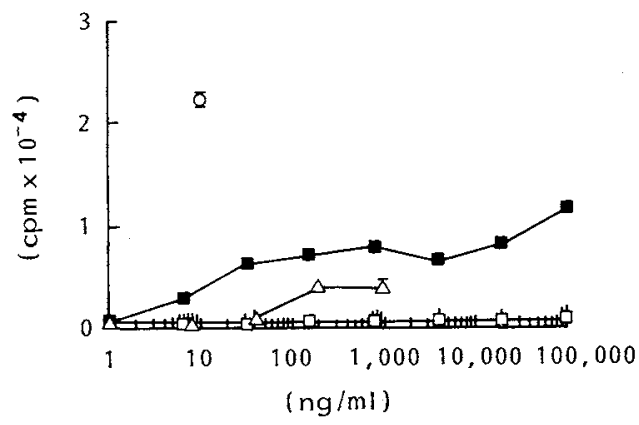

Fig. 6. Effect of extract of A71857 on G-CSF production by KM-102 cells.

O, IL-I (10 units/ml);

$\Delta$, extract of A71857.

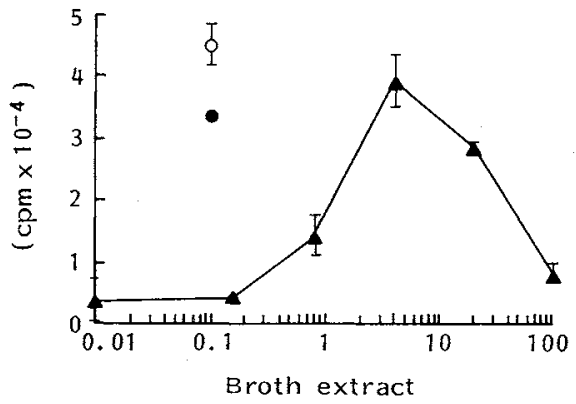

(응 of original broth volume)

are known to produce CSFs in the body ${ }^{26)}$, we chose bone marrow stromal cells as CSF producing cells in our screening program for the following reasons. 1) In normal adults, the site where blood cells are produced is limited to bone marrow. 2) DEXTER et al. have reported that the bone marrow stromal layer could support hematopoiesis in vitro in the absence of added growth factors ${ }^{13)}$. 3) Bone marrow stromal layer of clonal stromal cells can produce various kinds of hematopoietic growth factors including CSFs. 4) CSF inducers that act specifically on hematopoietic tissue are likely to show therapeutic effects without side effects that are observed in patients administered CSFs of currently known CSF inducers. For the sake of convenience, we used the clonal stromal cell line KM-102 for the screening instead of primary bone marrow stromal cells. KM-102 cells are also known to produce various kinds of hematopoietic factors and are thought to be useful for analysis of the mechanism of CSF production in stromal cells ${ }^{14,15,17,27)}$.

We chose a bioassay using factor dependent cell lines as a CSF assay system. Although CSF production can be measured by other methods (e.g., ELISA, northern blot analysis, colony forming assay), our bioassay offers the following advantages: 1) High sensitivity, 2) low running cost, 3) easy handling, and 4) rapid simultaneous analysis of many samples.

In our screening program, IL-1 was the most potent CSF inducer among the known inducers tested. Therefore, we used it as a positive control. IL-1 is known to upregulate CSF production in many cell populations and also has been reported to induce CSF production in bone marrow stromal cells. 
Furthermore, the administration of IL-1 accelerates hematopoietic reconstitution after chemotherapy or radiation induced myelosuppression, and the development of IL-1 as a therapeutic agent is currently in progress $^{28)}$. However, IL-1, which was originally discovered as an endogenous pyrogen, causes many side effects (fever, rigors, headache, transient hypoglycemia, etc.) when administered to patients ${ }^{28}$.

Regardless of structure, all activators of PKC possess similar moderate CSF inducing activities. IndolactumV $(-)$, which activates $\mathrm{PKC}$, possesses CSF inducing activity, while IndolactumV $(+)$, which does not activate PKC, has no CSF inducing activity. This suggests that the ability to upregulate CSF production and the ability to activate PKC are related. PKC may be involved in the signaling pathways which ultimately control CSF gene transcription.

Several investigators have reported that cyclic AMP elevating agents upregulate cytokine expression or production in many cell populations ${ }^{29 \sim 31)}$. For this reason, we tested the effect of a cyclic AMP analogue (DB-cAMP) and a cAMP-elevating agent (forskolin) on CSF production in this screening system. As shown in Fig. 5, these agents showed only slight inducing activities in our system, although GIMBLE et al. reported that forskolin potently induced IL- 6 in a murine bone marrow stromal cell system ${ }^{31)}$. Cytokine specificity or species specificity of regulation mechanisms may be responsible for the difference between the two systems.

Some immunomodulators derived from microorganisms have been used for the treatment of hematopoietic disorders. These immunomodulators are known to upregulate CSF production in several cells. Therefore we were interested in the effects of such immunomodulators on our screening system. Among the immunomodulators tested, only LPS stimulated CSF production. Although MDP and Bestatin are known to upregulate CSF production in macrophages, they had no effect on CSF production by human bone marrow stromal cells (Fig. 4 and Table 1). This observation may be relevant to the mild effects seen with MDP or Bestatin in vivo.

According to our results CSF inducers could be classified into 3 groups (Table 1): (a) Compounds that exhibit marked inducing activities like IL-1. (b) Compounds that exhibit moderate inducing activities like activators of PKC. (c) Compounds that exhibit slight inducing activities like cyclic AMP elevating agents. This classification may be useful for the selection of candidate samples identified by screening for further characterization as potentially novel CSF inducers.

Using this assay system, we found a strain that produced a compound with moderate inducing activity. The compound was identified as teleocidin-A which is known to be a strong activator of PKC (Fig. 3). The extract of another active strain showed marked inducing activity like IL-1, and this strain produced 3 novel compounds. These compounds showed no effect on the terminal differentiation of HL-60 cells. These results suggest that they belong to a new class of CSF inducers. Further details of their characterization will be published elsewhere.

Acknowledgments

We are very grateful to Drs. Ken-IChi Harigaya, Toshio Kitamura and James N. Ihle for supplying the useful cell lines. The expert technical assistance of JunKo IMADA and SATOMI ITOH is gratefully acknowledged.

\section{References}

1) MEtCALF, D.: The molecular biology and functions of the granulocyte-macrophage colony-stimulating factors. Blood 67: 257 267, 1986

2) SACHS, L.: The molecular control of blood cell development. Science 238: 1374 1379, 1987

3) Groopman, J. E.; J. M. Molina \& D. T. Scadden: Hematopoietic growth factors. Biology and clinical applications. N. Engl. J. Med. 321: 1449 1459, 1989

4) Tsubura, E.; I. Azuma \& T. UnE: Muroctasin, a muramyl dipeptide derivative. An introductory overview. Arzneimittelforschung 38: 951 952, 1988

5) Fukuoka, M.; M. Takada, N. Takifuji, N. Sakal, S. Ryu, N. Masuda, K. Matsui, S. Negoro, Y. Kusunoki \& E. Tubura: Restorative effect of muroctasin on leukopenia caused by anticancer chemotherapy in lung cancer. Comparative study by envelope method. Arzneimittelforschung 39: $90 \sim 93,1989$

6) Ichihara, N.; R. Kanazawa, S. Sasaki, K. Ono, T. Otani, F. Yamaguchi \& T. Une: Phase I study and clinical pharmacological study of muroctasin. Arzneimittelforschung 38: 1043 1069, 1988 
7) Tsuruo, T.; K. Naganuma, H. IIdA, T. Yamori, S. TsuKagoshi \& Y. SaKurar: Inhibition of lymph node metastasis of P388 leukemia by bestatin in mice. J. Antibiotics 34: 1206 1209, 1981

8) Akahane, K.; F. Yamaguchi, Y. Kita, T. Une \& Y. Osada: Stimulation of macrophages by muroctasin to produce colony-stimulating factors. Arzneimittelforschung 40: $179 \sim 183,1990$

9) Yamaguchi, F.; K. Akahane, T. Takashi \& W. Tsukada: Production of colony-stimulatingfactor from macrophages by muroctasin. Arzneimittelforschung 38: $983 \sim 986,1988$

10) Yamaguchi, F.; M. AKasaki \& W. Tsukada: Induction of colony-stimulating factor and stumulation of stem cell proliferation by injection of muroctasin. Arzneimittelforschung 38: 980 983, 1988

11.) Okamura, S.; F. Omori, K. HaGa, H. Baba, K. Sugimachi \& Y. Niho: Influence of bestatin on production of granulocytemacrophage colony-stimulating factor from human peripheral blood mononuclear cells in vitro. Acta Oncol. 29: 795 797, 1990

12) Eaves, C. J.; J. D. Cashman, R. J. Kay, G. J. Dougherty, T. Otsuka, L. A. Gaboury, D. E. Hogge, P. M. LANSDORP, A. C. EAVES \& R. K. Humphries: Mechanisms that regulate the cell cycle status of very primitive hematopoietic cells in long-term human marrow cultures. II. Analysis of positive and negative regulators produced by stromal cells within the adherent layer. Blood 78: $110 \sim 117,1991$

13) Dexter, T. M.; T. D. Allen \& L. G. LAJTHA: Conditions in controlling the proliferation of haemopoietic stem cells in vitro. J. Cell Physiol. 91: 335 344, 1977

14) Harigaya, K. \& H. Handa: Generation of functional clonal cell lines from human bone marrow stroma. Proc. Natl. Acad. Sci. U.S.A. 82: $3477 \sim 3480,1985$

15) Kohama, T.; H. Handa \& K. Harigaya: A burst-promoting activity derived from the human bone marrow stromal cell line KM-102 is identical to the granulocyte-macrophage colony-stimulating factor. Exp. Hematol. I6: 603 608, 1988

16) Slack, J. L; J. Nemunaitis, D. 3. Andrews \& J. W. Singer: Regulation of cytokine and growth factor gene expression in human bone marrow stromal cells transformed with simian virus 40. Blood 75: 2319 2327, 1990

17) Kawashima, I.; J. Ohsumi, H. K. Mita, T. K. Shimoda, H. Ishikawa, S. Sakakrbara, K. Miyadai \& Y. Takiguchi: Molecular cloning of cDNA encoding adipogenesis inhibitory factor and identity with interleukin-11. FEBS Lett. 283: $199 \sim 202,1991$

18) Paul, S. R.; Y. C. Yang, R. E. Donahue, S. Goldring \& D. A. Williams: Stromal cell-associated hematopoiesis: immortalization and characterization of a primate bone marrow-derived stromal cell line. Blood 77: 1723 1733, 1991

19) Kitamura, T.; T. Tange, T. Terasawa, S. Chiba, T. Kuwaki, K. Mryagawa, Y. F. Piao, K. Mryazono, A. URABE \& F. TAKAKU: Establishment and characterization of a unique human cell line that proliferates dependently on GM-CSF, IL-3, or erythropoietin. J. Cell Physiol. 140: 323 334, 1989

20) Holmes, K. L.; T. N. Palaszynski, H. C. Morse Fredrickson III \& J. N. Ihle: Correlation of cell-surface phenotype with the establishment of interleukin 3-dependent cell lines from wild-mouse murine leukemia virus-induced neoplasms. Proc. Natl. Acad. Sci. U.S.A. 82: 6687 6691, 1985

21) Kohama, T.; R. Enokita, T. Okazaki, H. Miyaoka, A. Torikata, M. Inukai, I. Kaneko, T. Kagasaki, Y. SAKAIDA, A. SATOH \& A. SHIRAISHI: Novel microbial metabolilites of the phoslactomycins family induce production of colony-stimulating factors by bone marrow stromal cells. I. Taxonomy, fermentation and biological properties J. Antibiotics 46: $1503 \sim 1511,1993$

22) Shirafuji, N.; S. Asano, S. Matsuda, K. Watari, F. Takaku \& S. Nagata: A new bioassay for human granulocyte colony-stimulating factor (hG-CSF) using murine myeloblastic NFS-60 cells as targets and estimation of its levels in sera from normal healthyl persons and patients with infectious and hematological disorders. Exp. Hematol. 17: $116 \sim 119,1989$

23) Fibbe, W. E.; D. J. Van, A. Billiad, H. M. Goselink, P. J. Voogt, E. G. Van, P. Ralph, B. W. Altrock \& J. H. FALKENBURG: Interleuckin 1 induces human marrow stromal cells in long-term culture to produce granulocyte colony-stimulating factor and macrophage colony-stimulating factor. Blood 71: 430 435, 1988

24) Rennick, D.; G. YanG, L. Gemmell \& F. Lee: Control of hemopoiesis by a bone marrow stromal cell clone: lipopolysaccharide- and interleukin-1-inducible production of colony-stimulating factors. Blood 69:682 691, 1987

25) Morstyn, G. \& A. W. Burgess: Hemopoietic growth factors: a review. Cancer Res. 48: 5624 5637, 1988

26) Gasson, J. C.: Molecular physiology of granulocyte-macrophage colony-stimulating factor. Blood 77: 1131 1145, 1991

27) HayaKawa, T.; K. Yamashita, J. Kishi \& K. HaRigaya: Tissue inhibitor of metalloproteinases from human bone marrow stromal cell line KM 102 has erythroid-potentiating activity, suggesting its possibly bifunctional role in the hematopoietic microenvironment. FEBS Lett. 268: 125 128, 1990

28) Crown, J.; A. Jakubowski, N. Kemeny, M. Gordon, C. Gasparetto, G. Wong, C. Sheridan, G. Toner, B. Meisenberg, J. Botet, J. Applewhite, S. Sinha, M. Moore, D. Kelsen, W. Buhles \& J. Gabrilove: A phase I trial of recombinant human interleukin- $1 \beta$ alone and in combination with myelosuppressive doses of 5-fluorouracil 
in patients with gastrointestinal cancer. Blood 78: 1420 1427, 1991

29) Vellenga, E.; D. V. B. VAN, W. J. DE \& M. R. HaliE: Simultaneous expression and regulation of G-CSF and IL-6 mRNA in adherent human monocytes and fibroblasts. Br. J. Haematol. 78: 14 18, 1991

30) YeE, C. S.; H. A. MESSNER \& M. D. MindeN: Regulation of interleukin-6 expression in the lymphoma cell line OCI-LY3. J. Cell Physiol. 148: 426 429, 1991

31) Gimble, J. M.; J. Hudson, J. Henthorn, X. X. Hua \& S. A. Burstein: Regulation of interleukin 6 expression in murine bone marrow stromal cells. Exp. Hematol. 19: 1055 1060, 1991 